\title{
PENGGUNAAN SCAFFOLDING UNTUK MEMPERBAIKI KESALAHAN SISWA SMP DALAM MENYELESAIKAN MASALAH MATEMATIKA
}

\author{
Claudya Zahrani Susilo \\ Prodi Pendidikan Guru Sekolah Dasar, Fakultas Ilmu Pendidikan, Universitas Hasyim Asy'ari Jombang \\ claudya_zahrani@yahoo.com
}

\begin{abstract}
Abstrak
Penelitian ini merupakan penelitian deskriptif kualitatif yang mendeskripsikan scaffolding untuk memperbaiki kesalahan siswa SMP dalam menyelesaikan masalah matematika. Subjek penelitian adalah siswa kelas VII yang mewakili level kemampuan matematika tinggi, sedang, dan rendah. Hasil penelitian menunjukkan bahwa kesalahan yang dilakukan oleh siswa dalam menyelesaikan masalah matematika adalah: (1) kesalahan menuliskan informasi yang ada dalam permasalahan, (2) kesalahan menuliskan rumus yang digunakan untuk menyelesaikan permasalahan, dan (3) kesalahan komputasi. Scaffolding yang digunakan untuk memperbaiki kesalahan siswa adalah: (1) meminta siswa membaca kembali permasalahan, (2) memberikan pertanyaan arahan kepada siswa, (3) meminta siswa merefleksi jawabannya, dan (4) meminta siswa mengecek kembali hasil pekerjaan.
\end{abstract}

Kata kunci: scaffolding, kesalahan, masalah matematika

\begin{abstract}
This research is a qualitative description research which describe scaffolding to fix the junior high students' error in solving mathematics problem. The research subject is 7 th grade student which represent mathematics ability in high, medium and low level. The result shows that the students' problem are (1) error in writing information of the problem, (2) error in writing the formula that is used in solving problem, and (3) komputational error. Scaffolding is used to fix the students' problem. Those are (1) asking students to reread the problem, (2) giving directional question to students, (3)asking students to reflect their answer,and (4) asking students to recheck the result of their problem.
\end{abstract}

Keywords: scaffolding, error, mathematics' problem

\section{PENDAHULUAN}

Pemecahan masalah merupakan salah satu fokus utama dalam pembelajaran matematika karena siswa diminta untuk mengembangkan cara berpikir mereka dalam menyelesaikan suatu permasalahan. Polya (1985) mengartikan pemecahan masalah merupakan suatu usaha mencari jalan keluar dari suatu kesulitan untuk mencapai tujuan yang tidak secara langsung dapat dicapai. Menurut Polya, pekerjaan utama seorang guru matematika adalah mengerahkan kemampuannya untuk membangun kemampuan siswa dalam menyelesaikan suatu permasalahan..

Tabel 1. Tahap Pemecahan Masalah

\begin{tabular}{|l|l|}
\hline \multicolumn{1}{|c|}{$\begin{array}{c}\text { Tahap Pemecahan } \\
\text { Masalah }\end{array}$} & \multicolumn{1}{c|}{ Deskripsi } \\
\hline Memahami masalah & $\begin{array}{l}\text { - Menyajikan kembali data } \\
\text { - Menentukan apa yang ditanyakan }\end{array}$ \\
\hline $\begin{array}{l}\text { Merencanakan } \\
\text { penyelesaian }\end{array}$ & $\begin{array}{l}\text { - Mengkonsruksi strategi penyelesaian masalah dari penyajian kembali data } \\
\text { - Membuat model matematika dari rancangan strategi penyelesaian yang telah } \\
\text { dibuat }\end{array}$ \\
\hline $\begin{array}{l}\text { Melaksanakan } \\
\text { penyelesaian }\end{array}$ & $\begin{array}{l}\text { - Menyatakan secara tertulis hubungan rencana pemecahan masalah yang } \\
\text { telah dibuat dengan konsep matematika tertentu. } \\
\text { - Memanipulasi ekspresi matematika pada pemodelan matematika sesuai } \\
\text { aturan sistem formal. }\end{array}$ \\
\hline
\end{tabular}




\begin{tabular}{|l|l|}
\hline $\begin{array}{l}\text { Memeriksa hasil yang } \\
\text { diperoleh }\end{array}$ & $\begin{array}{l}\text { - Menyimpulkan apakah jawaban yang diperoleh telah menjawab } \\
\text { permasalahan yang diberikan } \\
\text { - Memaknai simbol yang digunakan serta menginterpretasikan hasil jawaban } \\
\text { dari simbol formal ke dalam teks tertulis atau kata-kata. }\end{array}$ \\
\hline
\end{tabular}

Menurut pengalaman peneliti, masih ada beberapa siswa yang melakukan kesalahan dalam menyelesaikan suatu masalah matematika. Kesalahan yang dilakukan oleh siswa dianalisis untuk mengetahui jenis kesalahan yang dilakukan oleh siswa, letak kesalahan, penyebab kesalahan, dan cara mengatasi kesalahan. Kegiatan analisis kesalahan bertujuan untuk menemukan kesalahan, mengklarifikasi, dan melakukan tindakan perbaikan (Pateda, 1989: 35). Oleh karena itu, untuk memperbaiki kesalahan tersebut guru harus membimbing siswa melalui kegiatan tanya jawab. Bimbingan yang dilakukan oleh guru ini dikenal dengan istilah scaffolding.

Vygotsky (dalam Gunawan, 2012) mengemukakan bahwa scaffolding merupakan istilah dari proses yang digunakan oleh orang dewasa atau teman sebaya yang lebih mampu untuk menuntun anak-anak melalui Zone of Proximal Development mereka. Scaffolding memberikan sejumlah bantuan besar bagi seorang anak dalam tahap-tahap awal pembelajaran dan kemudian mengurangi bantuan tersebut untuk memberikan kesempatan kepada anak tersebut untuk mengambil alih tanggung jawab setelah ia mampu mengerjakan sendiri. Bantuan yang diberikan dapat berupa petunjuk, peringatan, dorongan menguraikan masalah menjadi bentuk lain yang dapat dipahami oleh anak. Vygotsky (1978: 86) mendefinisikan Zone of Proximal Development (ZPD) sebagai jarak antara level pengembangan aktual dan level pengembangan potensial dibawah bimbingan orang dewasa, atau kolaborasi dengan teman sebaya yang lebih mampu. Anghileri (2006) mengusulkan tiga level hirarki dari penggunaan scaffolding yang merupakan dukungan khusus dalam pembelajaran matematika, yaitu: Level 1 . Environmental provisions (classrooms organizations, artifact such as blocks), Level 2. Explaining, reviewing, and restructuring, dan Level 3. Developing conceptual thinking

Tabel 2. Level Penggunaan Scaffolding

\begin{tabular}{|c|c|}
\hline Level & Deskripsi \\
\hline $\begin{array}{l}\text { Level 1. Environmental } \\
\text { provisions } \quad \text { (classrooms } \\
\text { organizations, artifact } \\
\text { such as blocks) }\end{array}$ & $\begin{array}{l}\text { - Membantu siswa belajar dengan lingkungan yang diciptakan dalam } \\
\text { kelas. } \\
\text { - Menyediakan peralatan yang sesuai dengan materi pembelajaran, } \\
\text { sebagai lembar kerja siswa, tugas terstruktur serta hal-hal yang } \\
\text { mendukung siswa belajar mandiri. }\end{array}$ \\
\hline $\begin{array}{l}\text { Level 2. } \quad \text { Explaining, } \\
\text { reviewing, } \\
\text { restructuring }\end{array}$ & $\begin{array}{l}\text { - Tahap explaining, guru memberikan penjelasan tentang konsep } \\
\text { apabila siswa tidak tahu atau lupa. } \\
\text { - Tahap reviewing, guru bertugas memfokuskan kembali perhatian } \\
\text { siswa terhadap permasalahan yang dihadapi dan memberikan } \\
\text { kesempatan lebih lanjut untuk mengembangkan pemahaman mereka } \\
\text { sendiri daripada mengandalkan guru. } \\
\text { - Tahap Restructuring (restrukturisasi) merupakan interaksi guru dan } \\
\text { siswa yang bertujuan untuk mendorong refleksi siswa. }\end{array}$ \\
\hline $\begin{array}{l}\text { Level 3. Developing } \\
\text { conceptual thinking }\end{array}$ & $\begin{array}{l}\text { - Interaksi pengajaran yangmerupakan pengembangan pemikiran } \\
\text { konseptual dengan menciptakan kesempatan untuk mengungkapkan } \\
\text { pemahaman kepada orang lain. } \\
\text { - Siswa diminta untuk membuat koneksi dan mengembangkan } \\
\text { kemampuan menyelesaikan masalah, transfer keterampilan, dan } \\
\text { pemahaman yang dapat dikomunikasikan. }\end{array}$ \\
\hline
\end{tabular}


Berdasarkan penjabaran di atas, scaffolding yang digunakan untuk memperbaiki kesalahan siswa adalah scaffolding pada level 2 yaitu explaining, reviewing, and restructuring. Namun, dalam penelitian ini tidak melakukan scaffolding pada tahap explaining.

\section{METODE}

Jenis penelitian yang digunakan adalah penelitian kualitatif karena data yang diperoleh berupa kalimat dalam bentuk lisan maupun tertulis. Data yang berupa lisan/ucapan diperoleh dari hasil wawancara peneliti dengan subjek penelitian, dalam hal ini adalah siswa. Sedangkan data yang berupa tulisan diperoleh dari hasil pekerjaan siswa setelah diberikan scaffolding oleh peneliti. Penelitian ini merupakan penelitian deskriptif karena dalam penelitian ini meneliti individu secara mendalam untuk mendeskripsikan kesalahan dalam menyelesaikan pemecahan masalah matematika. Pelaksanaan penelitian di SMP Taman Siswa Malang dengan subjek penelitian adalah siswa kelas VII B yang terdiri dari 3 orang siswa yang mewakili level kemampuan matematika tinggi, sedang, dan rendah. Selanjutnya subjek yang memiliki kemampuan matematika tinggi disebut subjek 1 (S1), subjek yang memiliki kemampuan matematika sedang disebut subjek 2 (S2), dan subjek yang memiliki kemampuan matematika rendah disebut subjek 3 (S3). Teknik penentuan subjek penelitian menggunakan teknik purpose sampling karena didasarkan pada kriteria atau pertimbangan tertentu.

Teknik pengumpulan data pada penelitian ini dilakukan melalui: (1) tes pemecahan masalah materi perbandingan, (2) wawancara dengan siswa, dan (3) dokumentasi berupa foto hasil pekerjaan siswa dalam menyelesaikan permasalahan.

Berikut pedoman wawancara dalam pemberian scaffolding.

Tabel 3. Pedoman Wawancara dalam Pemberian Scaffolding

\begin{tabular}{|c|c|c|}
\hline No. & $\begin{array}{l}\text { Tahap Pemecahan } \\
\text { Masalah } \\
\end{array}$ & Deskripsi Pertanyaan \\
\hline 1. & Memahami masalah & $\begin{array}{l}\text { - Informasi apa saja yang ada dalam permasalahan? } \\
\text { - Apakah masih ada informasi yang belum kalian tuliskan? } \\
\text { - Tuliskan informasi yang belum dituliskan! } \\
\text { - Apa yang ditanyakan dalam permasalahan? }\end{array}$ \\
\hline 2. & $\begin{array}{l}\text { Merencana-kan } \\
\text { penyelesai-an }\end{array}$ & $\begin{array}{l}\text { - Konsep apa yang kalian gunakan untuk menyelesaikan } \\
\text { permasalahan? } \\
\text { - Mengapa konsep tersebut dipakai untuk menyelesaikan } \\
\text { permasalahan? } \\
\text { - Apa langkah awal yang harus dicari untuk menjawab } \\
\text { pertanyaan? }\end{array}$ \\
\hline 3. & $\begin{array}{l}\text { Melaksana-kan } \\
\text { penyelesai-an }\end{array}$ & $\begin{array}{l}\text { - Apa langkah selanjutnya untuk memperoleh penyelesaian? } \\
\text { - Bagaimana cara mencarinya? }\end{array}$ \\
\hline 4. & $\begin{array}{l}\text { Memeriksa hasil yang } \\
\text { diperoleh }\end{array}$ & $\begin{array}{l}\text { - Apakah jawaban yang kalian peroleh sudah menjawab } \\
\text { permasalahan? } \\
\text { - Bagaimana cara mengecek apakah jawaban yang diperoleh } \\
\text { sudah dapat menjawab pertanyaan? }\end{array}$ \\
\hline
\end{tabular}

Teknik analisis data dilakukan dengan langkah-langkah: (1) mereduksi data, yaitu memilih, menyederhanakan, dan menggolongkan siswa yang melakukan kesalahan; (2) menyajikan data yaitu melakukan penyusunan jenis kesalahan yang dilakukan oleh siswa berdasarkan level kemampuan matematika siswa, dan (3) menarik kesimpulan yaitu melakukan kegiatan scaffolding yang sesuai dengankesalahan yang dilakukan masingmasing level kemampuan matematika siswa. Peneliti melakukan teknik pemeriksaan keabsahan data agar diperoleh 
temuan dan interpretasi yang absah. Teknik pemeriksaan keabsahan data yang dilakukan adalah teknik keabsahan yang dipaparkan oleh Moleong (2014) yaitu triangulasi data. Triangulasi yang digunakan adalah triangulasi sumber dengan membandingkan data hasil tes siswa, wawancara dengan siswa serta diskusi dengan guru pengajar matematika di kelas tersebut.

\section{HASIL DAN PEMBAHASAN}

Kesalahan yang dilakukan oleh siswa perlu diperbaiki supaya siswa tidak mengulangi kesalahan yang sama dan siswa dapat menyelesaikan permasalahan secara benar. Oleh karena itu, guru harus membimbing siswa melalui kegiatan tanya jawab untuk memperbaiki kesalahan yang dilakukan oleh siswa. Berikut uraian scaffolding yang digunakan pada setiap level pemahaman siswa.

\section{Scaffolding untuk Mengatasi Kesalahan S1}

Pada tahap memahami masalah siswa melakukan kesalahan ketika menuliskan $A$ dan $B=2,4 \quad \mathrm{~cm}$. Scaffolding yang digunakan untuk memperbaiki kesalahan S1 adalah scaffolding pada tahap reviewing. Kesalahan lain yang dilakukan oleh S1 adalah ketika menuliskan rumus $J S=S \times$ $J P$ dan ketika S1 menuliskan satuan "km" pada akhir kalkulasi. Scaffolding yang digunakan untuk memperbaiki kesalahan ketika menuliskan rumus jarak sebenarnya adalah scaffolding tahap restructuring. Sedangkan scaffolding yang digunakan untuk memperbaiki kesalahan S1 ketika menuliskan satuan pada akhir kalkulasi adalah scaffolding tahap reviewing. Pada tahap memeriksa hasil yang diperoleh, S1 melakukan kesalahan dengan tidak menyimpulkan apakah hasil jawaban yang diperoleh menjawab pertanyaan. Scaffolding yang digunakan yaitu scaffolding tahap reviewing dengan memberikan probing question (pertanyaan menyelidiki).

\section{Scaffolding untuk Mengatasi Kesalahan S2}

Pada permasalahan 1 S2 melakukan kesalahan dalam menuliskan informasi yang diketahui ketika memahami masalah. S2 menuliskan informasi yang diketahui yaitu $1: 10.000 .000$. S2 tidak menuliskan makna dari bilangan tersebut. Selain itu, S2 masih kurang lengkap dalam menuliskan informasi yang diketahui, yaitu waktu tiba bus pukul 10.30. Selanjutnya pada tahap merencanakan penyelesaian S2 melakukan kesalahan dalam menuliskan rumus jarak sebenarnya $J S=J P \times S . \quad$ S2 juga melakukan kesalahan ketika melakukan perhitungan mencari nilai jarak sebenarnya. Proses perhitung yang dituliskan S2 yaitu $J S=J P \times S=1: 10.000 .000 \times$ $24.000 .000 \mathrm{~cm}=240 \mathrm{~km}$. Selain itu, S2 melakukan kesalahan dalam menuliskan hasil perhitungan mencari waktu tempuh bus. S2 menuliskan bahwa waktu tempuh bus adalah 240:80 =3.00. Pada tahap akhir penyelesaian permasalahan, S2 tidak melakukan pemeriksaan hasil jawaban. Hal ini ditunjukkan dengan S2 tidak menyimpulkan hasil penyelesaiannya.

Scaffolding yang digunakan untuk memperbaiki kesalahan S2 ketika melakukan kesalahan pada tahap memahami permasalahan yaitu scaffolding tahap reviewing dengan memberikan prompting and probing question (pertanyaan mengingat dan menyelidiki). Sedangkan scaffolding yang digunakan untuk memperbaiki kesalahan S2 ketika menuliskan rumus jarak sebenarnya yaitu scaffolding tahap restructuring. Selanjutnya untuk memperbaiki kesalahan S2 ketika menuliskan hasil perhitungan waktu tempuh bus adalah scaffolding tahap reviewing dengan memberikan prompting and probing question (pertanyaan mengingat dan menyelidiki). Ketika S2 tidak menuliskan kesimpulan hasil penyelesaian yang diperoleh, peneliti menggunakan scaffolding tahap reviewing dengan memberikan probing question (pertanyaan menyelidiki). 


\section{Scaffolding untuk Mengatasi Kesalahan S3}

Ketika menyelesaikan permasalahan 1 , S3 melakukan kesalahan pada tahap memahami permasalahan. Kesalahan S3 pada tahap ini yaitu ketika menuliskan jarak peta $=2,4$ dan kecepatan $=80 \mathrm{~km}$. S3 tidak menuliskan satuan pada jarak peta dan S3 salah dalam menuliskan satuan kecepatan. Scaffolding yang digunakan untuk memperbaiki kesalahan S3 yaitu scaffolding tahap reviewing dengan memberikan probing question (pertanyaan menyelidiki). Kesalahan lain yang dilakukan oleh S3 yaitu salah menuliskan rumus jarak sebenarnya dan menuliskan rumus mencari waktu tempuh bus pada tahap merencanakan penyelesaian. S3 menuliskan rumus jarak sebenarnya yaitu $J S=S \times J P$. Scaffolding yang digunakan untuk memperbaiki kesalahan ini adalah scaffolding tahap restructuring. Sedangkan kesalahan menulis rumus untuk mencari waktu tempuh bus yaitu $K=\frac{J}{W}=\frac{240}{80}=$ 3.Scaffolding yang digunakan untuk memperbaiki kesalahan S3 yaitu scaffolding tahap reviewing dengan memberikan probing question (pertanyaan menyelidiki). Pada tahap melaksanakan penyelesaian masalah, S3 melakukan kesalahan dalam kalkulasi jarak sebenarnya dan menuliskan satuan "km" pada hasil akhir kalkulasi. S3 menuliskan $J S=S \times$ $J P=1: 10.000 .000 \times 2,4=$ $240.000 .000=240 \mathrm{~km}$. Scaffolding yang digunakan untuk memperbaiki kesalahan S3 dalam menuliskan rumus jarak sebenarnya yaitu scaffolding tahap restructuring. Sedangkan scaffolding yang digunakan untuk memperbaiki kesalahan dalam menuliskan satuan pada hasil akhir kalkulasi yaitu scaffolding tahap reviewing dengan memberikan probing question (pertanyaan menyelidiki).

Scaffolding adalah suatu proses kegiatan yang dilakukan oleh orang dewasa atau teman sebaya yang lebih mampu untuk menuntun anak melewati kemampuan awal yang dimiliki anak (Vygotsky, 1978). Istilah scaffolding dapat diartikan sebagai bantuan atau dukungan. Menurut Anghileri (2006) terdapat tiga level hirarki dari penggunaan scaffolding. Dalam penelitian ini level yang digunakan adalah level 2, yaitu reviewing and restructuring karena scaffolding yang digunakan berupa pertanyaan-pertanyaan yang mengarah pada hasil penyelesaian serta peneliti menyederhanakan permasalahan agar siswa dapat menyelesaikan permasalahan.

Pada tahap reviewing guru memiliki tugas untuk memfokuskan kembali perhatian siswa pada permasalahan dan memberikan kesempatan lebih lanjut untuk mengembangkan pemahaman mereka sendiri (Anghileri, 2006). Kegiatan yang dilakukan pada tahap ini adalah guru meminta siswa untuk menjelaskan atau mengungkapkan hasil pekerjaannya serta memperhatikan kesalahan yang dilakukan. Selain itu, guru dapat memberikan pertanyaan yang dapat membantu siswa untuk memperbaiki kesalahannya. Kegiatan-kegiatan di atas sesuai dengan interaksi dalam tahap reviewing yang dikemukakan oleh Anghileri (2006) yaitu looking, touching, and verbalizing (melihat, memahami, dan mengungkapkan apa yang siswa lihat dan pikirkan) serta prompting and probing question (pertanyaan mengingat dan menyelidiki).

Peneliti memberikan scaffolding tahap reviewing pada ketiga siswa yang menjadi subjek penelitian. Scaffolding yang diberikan pada S1 berupa probing question ketika S1 menuliskan jarak antara kota $A$ dan $B=2,4 \mathrm{~cm}$. Selain itu, pemberian scaffolding berupa pertanyaanjuga diberikan untuk memperbaiki kesalahan S1 ketika tidak menuliskan kesimpulan dari hasil penyelesaiannya. Hal ini merujuk pada hasil penelitian Nurohmah dan Setianingsih (2014) yang memaparkan bahwa peneliti memberikan scaffolding kepada siswa berkemampuan tinggi berupa pertanyaan apakah ada hubungan antara hasil penyelesaian dengan apa yang ditanyakan dalam permasalahan. S1 juga melakukan kesalahan representasi verbal pada permasalahan kedua, yaitu S1 menuliskan sisa waktu 12 hari. Peneliti menggunakan scaffolding berupa probing question yang mengarahkan siswa untuk menjelaskan makna dari pernyataan yang dituliskan. Hal ini sejalan dengan Cahyono (2010) yang 
memaparkan bahwa guru memberikan pertanyaan penyelidikan agar siswa menjelaskan apa yang dipikirkan dan dipahami.

Scaffolding yang diberikan pada S2 pada tahap reviewing adalah probing question untuk memperbaiki kesalahan S2 yang belum lengkap menuliskan informasi yang diketahui. Ketika S2 menuliskan hasil kalkulasi waktu tempuh bus juga melakukan kesalahan dengan menuliskan simbol "3.00". Peneliti menggunakan scaffoldingprompting and probing question untuk mengetahui maksud penulisan S2. Pada permasalahan 2, S2 juga melakukan kesalahan dalam menuliskan model matematika yaitu $66 x=\frac{2422}{66}$. S2 tidak menuliskan operasi hitung matematika serta salah dalam menuliskan model matematika. Scaffolding yang digunakan untuk memperbaiki kesalahan S2 yaitu probing question yang mengarah pada konsep hitung yang digunakan untuk menyelesaikan model matematika. Kesalahan-kesalahan yang dilakukan S3 yaitu kesalahan dalam menuliskan satuan jarak dan satuan kecepatan, kesalahan menuliskan rumus mencari waktu tempuh, dan kesalahan mengartikan simbol " $x$ " sebagai hasil selesaian. Scaffolding yang digunakan berupa prompting and probing question.

Pada tahap restructuring terjadi interaksi antara guru dan siswa yang bertujuan untuk mendorong refleksi siswa (Anghileri, 2006). Kegiatan yang dilakukan pada tahap restructuringadalah guru membantu siswa menyelesaikan permasalahan dengan mengubah permasalahan menjadi permasalahan yang sederhana. Scaffolding pada tahap restructuring diberikan kepada ketiga siswa pada permasalahan 1 untuk memperbaiki kesalahan konsep skala untuk mencari jarak sebenarnya karena ketiga siswa melakukan kesalahan yang sama yaitu menuliskan $J S=S \times J P . \quad$ Sehingga peneliti menyederhanakan permasalahan tersebut dengan meminta siswa mensubstitusikan informasi yang diketahui pada rumus skala yang telah dituliskan siswa. Hasil ini sejalan dengan penelitian Nurohmah dan
Setianingsing (2014) yang memaparkan bahwa peneliti memberikan scaffolding tahap restructuring untuk menyederhanakan permasalahan berupa membacakan masalah dengan memberikan penekanan intonasi pada hal yang penting.

\section{SIMPULAN}

Berdasarkan uraian scaffolding yang digunakan memperbaiki kesalahan siawa pada setiap level pemahaman maka dapat disimpulkan bahwascaffolding yang diberikan kepada subjek berkemampuan matematika tinggi untuk memperbaiki kesalahan pada tahap memahami masalah yaitu scaffolding tahap reviewing. Sedangkan scaffolding yang diberikan untuk memperbaiki kesalahan pada tahap merencanakan penyelesaian yaitu scaffolding tahap restructuring. Pada tahap melaksanakan penyelesaian dan memeriksa hasil penyelesaian, scaffolding yang diberikan yaitu scaffolding tahap reviewing.

Selanjutnya scaffolding yang diberikan kepada siswa berkemampuan matematika sedang pada tahap memahami permasalahan yaitu scaffolding tahap reviewing. Sedangkan scaffolding yang diberikan untuk memperbaiki kesalahan pada tahap merencanakan penyelesaian yaitu scaffolding tahap restructuring. Ketika memperbaiki kesalahan pada tahap melaksanakan penyelesaian, scaffolding yang digunakan yaitu scaffolding tahap reviewing dan tahap restructuring. Scaffolding yang digunakan untuk memperbaiki kesalahan pada tahap memeriksa hasil penyelesaian yaitu scaffolding tahap reviewing.

Scaffolding yang digunakan untuk memperbaiki kesalahan pada siswa berkemampuan matematika rendah ketika memahami masalah yaitu scaffolding tahap reviewing. Sedangkan pada tahap merencanakan penyelesaian, scaffolding yang digunakan untuk memperbaiki kesalahan yaitu scaffolding tahap restructuring. Kesalahan pada tahap melaksanakan dan memeriksa hasil penyelesaian diperbaiki dengan scaffolding tahap reviewing.

Penelitian ini merupakan penelitian tentang deskripsi jenis-jenis scaffolding 
yang digunakan untuk memperbaiki kesalahan yang dilakukan oleh siswa kelas VII SMP dalam menyelesaikan permasalahan materi perbandingan. Berdasarkan hasil temuan dan pembahasan, peneliti memberikan beberapa saran kepada guru. Sebaiknya guru sering mengecek pemahaman siswa mengenai suatu konsep agar siswa tidak melakukan kesalahan dalam memanipulasi rumus maupun

\section{DAFTAR PUSTAKA}

Anghileri, J. 2006. Scaffolding Practices That Enhance Mathematics Learning. Journal of Mathematics Teacher Education, 9. 33-52.

Cahyono, A. N. (2010). Vygotskian Perspective: Proses Scaffolding untuk mencapai Zone of Proximal Development (ZPD) Peserta didik dalam Pembelajaran Matematika. Jurnal Jurusan Matematika FMIPA Universitas Negeri Semarang.

Fadhilah, S. 2009. Kemampuan Pemecahan Masalah Matematis dalam Pembelajaran Matematika. Prosiding Seminar Nasional Penelitian, Pendidikan, dan Penerapan MIPA Fakultas MIPA, Universitas Negeri Yogyakarta.

Gunawan, B. 2012. Penerapan Teori Belajar Vygotsky dalam Interaksi Belajar Mengajar. (Online). http://www.kompasiana.com/baktiguna wan/penerapan-teori-belajar-vygotskydalam-interaksi-belajarmengajar_550d985b8133115d22b1e4d $\underline{8}$, diakses tanggal 16 Februari 2017.

Moleong, L. J. 2014. Metode Penelitian Kualitatif. Bandung: PT Remaja Rosdakarya.

Musdhalifah, U., Sutinah, \& Kurniasari, I. 2013. Analisis Kesalahan Siswa Kelas VII dalam Memecahkan Masalah Non Rutin yang Terkait dengan Bilangan Bulat Berdasarkan Tingkat Kemampuan Matematika di SMPN 31 Surabaya. (Online). http:// jurnalmahasiswa.unesa.ac.id/index.php /mathedunesa/article/view/3905, diakses tanggal 2 Maret 2016. persamaan yang digunakan untuk menyelesaikan permasalahan, mengingatkan siswa untuk memperhatikan penulisan simbol-simbol matematika ketika mempelajari suatu materi agar siswa tidak melakukan kesalahan, dan mengingatkan siswa untuk menuliskan apa yang ditanyakan dalam permasalahan untuk menghindari kekurangtelitian siswa.

NTCM. 2000. Principle and Standards for School Mathematics. America: Kathleen Beall.

Nurohmah, S. D. \& Setianingsih, R. 2014. Implementasi Scaffolding untuk Mengatasi Kesulitan Siswa Kelas X SMK Kartika 1 Surabaya dalam Menyelesaikan Soal Cerita pada Materi Program Linear. Jurnal Ilmiah Pendidikan Matematika Unesa Vol.3, No.3.

Pateda, M. 1989. Analisis Kesalahan. NTT: Nusa Indah.

Polya, G., 1985., How to Solve It: A New Aspect of Mathematics Method (2 ed). Princeton, N.J., Princeton University Press.

Vygotsky, L. S. 1978. Mind in Society: The Development of Higher Psychological Processes. In M. Cole, V. JohnSteiner, S. Scriber and E. Souberman (eds). Cambridge, M.A.: Harvard Universi 